\title{
Plasma orexin-A and ghrelin levels in patients with chronic obstructive pulmonary disease: Interaction with nutritional status and body composition
}

\author{
GAMZE AKBULUT ${ }^{1}$, MAKBULE GEZMEN-KARADAĞ ${ }^{1}$, YASEMIN ERTAȘ ${ }^{1}$, BANUGÜL BARUT UYAR $^{1}$, \\ EMINE YASSIBAŞ ${ }^{1}$, DUYGU TÜRKÖZÜ ${ }^{1}$, FERIDE ÇELEBi ${ }^{1}$, ÖZGE TUĞÇE PAŞAOĞLU ${ }^{1}$, \\ ONUR TOKA $^{2}$, HILAL YILDIRAN ${ }^{1}$, NEVIN ŞANLIER ${ }^{1}$ and NURDAN KÖKTÜRK ${ }^{3}$ \\ ${ }^{1}$ Department of Nutrition and Dietetics, Faculty of Health Sciences, Gazi University, Ankara 06500; ${ }^{2}$ Department of Statistics, \\ Hacettepe University, Ankara 06800; ${ }^{3}$ Department of Pulmonary Diseases, Faculty of Medicine, \\ Gazi University, Ankara 06560, Turkey
}

Received November 4, 2013; Accepted February 26, 2014

DOI: $10.3892 /$ etm.2014.1611

\begin{abstract}
Orexin-A and ghrelin are two important polypeptides that stimulate food intake, however, there is a lack of sufficient information concerning their plasma levels in patients with chronic obstructive pulmonary disease (COPD). The aim of the present study was to investigate the association between plasma orexin-A and ghrelin levels with food consumption and body composition in patients with stable phase COPD. In total, 40 patients (age, 44-80 years; male, 31; female 9) who were in the stable phase of COPD were included in the study. Blood samples for plasma orexin-A and ghrelin analysis were collected after 8-12 h of fasting; certain anthropometric measurements were obtained and a 24-h dietary recall was recorded. The mean plasma orexin-A levels in the male and female patients were $1.3 \pm 0.37$ and $1.4 \pm 0.13 \mathrm{ng} / \mathrm{ml}$, respectively,

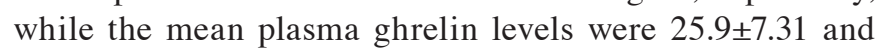
$27.3 \pm 8.54 \mathrm{ng} / \mathrm{ml}$, respectively. No significant correlation was observed between the body mass index and plasma orexin-A and ghrelin levels or between the plasma ghrelin levels and dietary nutrient intake $(\mathrm{P}>0.05)$. The plasma orexin-A levels were demonstrated to be higher in patients with a higher dietary total fibre intake $(r=0.303, P=0.022)$. A similar correlation was observed between plasma orexin-A levels and dietary intake of soluble $(r=0.033, \mathrm{P}=0.029)$ and insoluble $(\mathrm{r}=0.335, \mathrm{P}=0.024)$ fibre, as well as between the daily consumption of calcium and the levels of plasma orexin-A $(r=0.065, P=0.046)$. Therefore, the results of the present study indicated that a positive correlation
\end{abstract}

Correspondence to: Dr Makbule Gezmen-Karadağ, Department of Nutrition and Dietetics, Faculty of Health Sciences, Gazi University, Emniyet Mahallesi, No. 16 Muammer Yaşar Bostancı Caddesi, Ankara 06500, Turkey

E-mail: mgezmen@gazi.edu.tr

Key words: orexin-A, ghrelin, chronic obstructive pulmonary disease, diet, anthropometric measurements existed between dietary nutrient intake and plasma orexin-A levels in patients with COPD.

\section{Introduction}

Chronic obstructive pulmonary disease (COPD) has a high incidence worldwide and a high mortality rate. According to data from the World Health Organization (WHO), it is predicted that COPD, which was the sixth most common cause of mortality in 1990, is likely to the third most common cause by $2020(1,2)$.

Malnutrition is frequently reported in COPD patients and is an indicator of poor prognosis (3-8). Being underweight is associated with a high mortality rate in patients with COPD (7), which may be explained by the weakening of the respiratory and skeletal muscles (9).

Specific hypothalamic neuropeptides, including orexin, are generally affected by nutritional status and dietary food intake $(10,11)$. Ghrelin is also an important polypeptide that stimulates food intake $(12,13)$. Orexins play an important role in various physiological events, including the stress response and the sleep/wake cycle (14). In a previous study, orexin-A levels in patients with COPD were reported to be lower than those in the control group. Furthermore, the levels of orexin-A were found to be lower in underweight COPD patients when compared with those in normal weight patients with COPD (8). Ghrelin stimulates food intake, increases adiposity by decreasing lipid oxidation and maintains the energy balance $(12,13,15)$. Itoh et al (16) indicated that plasma ghrelin levels were higher in underweight patients with COPD than in normal weight patients with COPD.

There are a limited number of studies that evaluate the association between plasma orexin-A and ghrelin levels with body composition and dietary intake in patients with COPD. To the best of our knowledge, there are no similar studies concerning patients with COPD in Turkey. For this reason, the present study aimed to investigate a possible correlation between plasma orexin-A and ghrelin levels with body composition and food consumption. 


\section{Materials and methods}

Subjects. A total of 40 patients with stable phase COPD (44-80 years old) who were admitted to the Department of Pulmonary Diseases, Faculty of Medicine, Gazi University (Ankara, Turkey) between July 2012 and July 2013 volunteered for this study. The study was conducted in accordance with the regulations of Gazi University Clinical Research Ethics Committee and each participant signed a voluntary participation form. Due to financial problems, we did not use control patients in this research.

Experimental design. Following a fasting period of 8-12 h, 7-ml blood samples were extracted from the patients and into tubes containing EDTA (Phoenix Pharmaceuticals, Inc., Belmont, CA, USA). A protease inhibitor, aprotinin, was added to the tubes ( $100 \mu \mathrm{l} / \mathrm{ml}$ blood), as recommended by the manufacturer of the ELISA kits (Phoenix Pharmaceuticals, Inc.). The samples were centrifuged at $1,600 \mathrm{x} \mathrm{g}$ at $4^{\circ} \mathrm{C}$ for $15 \mathrm{~min}$. The plasma samples were separated and maintained at $-32^{\circ} \mathrm{C}$ until required for analysis $(17,18)$. The samples were analysed in duplicates.

Orexin-A and ghrelin levels in the plasma samples were analysed via an ELISA method, an immunoassay that determines antigen-antibody interactions, using ELISA kits purchased from Phoenix Pharmaceuticals, Inc. $(17,18)$. According to the manufacturer's instructions, the minimum detection limits of orexin-A and ghrelin were 0.2 and $0.13 \mathrm{ng} / \mathrm{ml}$, respectively.

Data were collected from the patients during a face-to-face interview with qualified dieticians. In the interview, a questionnaire was used to determine the general features (age, gender, educational status and occupation), smoking habits, alcohol use and diet habits of the patients. Food consumption was measured with a 24-h dietary recall. During the interview, food models and photos of common Turkish foods of various portion sizes, as well as household cups and measures, were used to assess the type and amount of food and beverage consumed during the previous day (19). The average daily energy and macro- and micronutrient intakes were calculated using the computer software Nutrition Information Systems (BeBiS, Version 7.0, Pasific Company, Stuttgart, Germany). These values were compared with the recommended daily allowance values to determine the energy and nutrient requirement meeting status and the requirement meeting percentages were calculated (20). The dietary guidelines for Turkey were used for the assessment of specific nutrients (21).

All anthropometric measurements were obtained by trained dieticians, as described in a previous study (11). Body composition parameters, including weight, total body water, fat mass, lean mass and fat percentages of the patients, were measured using an InBody720 Bioelectrical Impedance Analyzer (Biospace, Seoul, Korea). The body mass index (BMI) was calculated as weight/(height $)^{2}$ and BMI classifications were determined according to the WHO standards (22).

Statistical analysis. Data analysis was performed using SPSS software, version 16.0 (SPSS, Inc., Chicago, IL, USA). As the data did not exhibit normal distribution, the median and interquartile range values were used to conduct statistical analyses of the daily dietary energy and nutrient intakes and body compositions, however, the mean and SD values are also presented. The Mann-Whitney U test was used for statistical comparison of the genders. Spearman's correlation test was used to analyse correlations between the parameters, including the correlation between energy and nutrient intake and body composition with orexin-A and ghrelin levels; regression analysis was performed for the associated parameters. The statistical significance level was selected as $95 \%$ and $\mathrm{P}<0.05$ was considered to indicate a statistically significant difference (23).

\section{Results}

Patient characteristics. In total, 40 adult patients with COPD, 9 female $(22.5 \%)$ and 31 male $(77.5 \%)$ with an average age of $65.0 \pm 14.50$ years, volunteered for the study. The general features and plasma orexin-A and ghrelin levels of the patients are shown in Table I. Plasma orexin-A levels in male and female patients were found to be $1.3 \pm 0.37$ and $1.4 \pm 0.13 \mathrm{ng} / \mathrm{ml}$, respectively, whereas the average plasma ghrelin levels were $25.9 \pm 7.31$ and $27.3 \pm 8.54 \mathrm{ng} / \mathrm{ml}$, respectively. No statistically significant differences were observed between the two groups with regard to age, time course of COPD diagnosis and plasma orexin-A and ghrelin levels $(\mathrm{P}>0.05)$.

Antropometric measurements. Anthropometric measurements of the patients are presented in Table II. When differences between genders were investigated, significant differences $(\mathrm{P}<0.05)$ were identified for the basal metabolic rate $(\mathrm{P}=0.004)$, lean body mass $(\mathrm{P}=0.004)$, total body water $(\mathrm{P}=0.004)$, skeletal-muscle weights $(\mathrm{P}=0.009)$ and intracellular $(\mathrm{P}=0.004)$ and extracellular $(\mathrm{P}=0.000)$ fluid amounts between the two groups.

Orexin-A and ghrelin levels with BMI. The highest plasma orexin-A levels were identified in underweight female patients $\left(\mathrm{BMI}<18.5 \mathrm{~kg} / \mathrm{m}^{2}\right)$ and the lowest levels were identified in female patients with a normal BMI. However, as the number of underweight female patients was low, they were excluded from the statistical evaluation. Plasma orexin-A levels were only higher than those in female patients in male patients with a normal BMI $\left(18.5-24.9 \mathrm{~kg} / \mathrm{m}^{2}\right)$. When the patients were classified according to their BMIs, the plasma orexin-A levels of the BMI groups were observed to be similar ( $\mathrm{P}>0.05$; Fig. 1). Similarly, no significant difference in ghrelin levels was identified according to the patient BMI classification $(\mathrm{P}>0.05$; Fig. 2).

Dietary intake and requirements. Daily average dietary energy and nutrient intakes and requirement meeting percentages are shown in Table III. Female patients met $89.6 \%$ of their daily energy requirement, whereas male patients met $79.0 \%$ of their energy requirement. While the rate of meeting the protein requirement was lower in female patients, no statistically significant difference was identified between the genders. The dietary saturated fatty acid intake was observed to be significantly higher in female patients than in male patients $(\mathrm{P}=0.05)$. The daily average dietary fibre intake was $\sim 21.4 \pm 11.94 \mathrm{~g}$. No significant differences were identified between the groups with 
Table I. General features and the plasma orexin-A and ghrelin levels of the patients.

\begin{tabular}{|c|c|c|c|c|c|c|c|}
\hline \multirow[b]{2}{*}{ Feature } & \multicolumn{2}{|c|}{ Female $(n=9)$} & \multicolumn{2}{|c|}{ Male $(n=31)$} & \multicolumn{2}{|c|}{ Total $(n=40)$} & \multirow[b]{2}{*}{ P-value } \\
\hline & Mean \pm SD & Median/IQR & Mean \pm SD & Median/IQR & Mean \pm SD & Median/IQR & \\
\hline Age (years) & $61.3 \pm 8.54$ & $62.0 \pm 11.50$ & $65.5 \pm 8.82$ & $65.0 \pm 14.00$ & $64.6 \pm 8.83$ & $65.0 \pm 14.50$ & 0.237 \\
\hline $\begin{array}{l}\text { Time course of COPD } \\
\text { diagnosis (months) }\end{array}$ & $42.8 \pm 39.92$ & $60.0 \pm 69.00$ & $55.0 \pm 49.99$ & $54.0 \pm 92.00$ & $52.3 \pm 47.70$ & $57.0 \pm 79.75$ & 0.436 \\
\hline Orexin-A (ng/ml) & $1.4 \pm 0.13$ & $1.38 \pm 0.20$ & $1.3 \pm 0.37$ & $1.25 \pm 0.40$ & $1.3 \pm 0.34$ & $1.32 \pm 0.37$ & 0.308 \\
\hline Ghrelin (ng/ml) & $27.3 \pm 8.54$ & $26.2 \pm 10.90$ & $25.9 \pm 7.31$ & $27.9 \pm 13.90$ & $26.2 \pm 7.51$ & $27.0 \pm 12.96$ & 0.771 \\
\hline
\end{tabular}

$\mathrm{IQR}$, interquartile range; COPD, chronic obstructive pulmonary disease.

Table II. Body composition of the patients.

\begin{tabular}{|c|c|c|c|c|c|c|c|}
\hline \multirow[b]{2}{*}{ Body feature } & \multicolumn{2}{|c|}{ Female $(n=9)$} & \multicolumn{2}{|c|}{ Male $(\mathrm{n}=31)$} & \multicolumn{2}{|c|}{ Total $(n=40)$} & \multirow[b]{2}{*}{ P-value } \\
\hline & Mean $\pm \mathrm{SD}$ & Median/IQR & Mean $\pm \mathrm{SD}$ & Median/IQR & Mean $\pm \mathrm{SD}$ & Median/IQR & \\
\hline Body weight (kg) & $72.2 \pm 19.45$ & $68.1 \pm 28.00$ & $78.7 \pm 17.02$ & $76.4 \pm 19.60$ & $77.2 \pm 17.55$ & $74.5 \pm 21.60$ & 0.271 \\
\hline Height $(\mathrm{cm})$ & $160.6 \pm 4.88$ & $160.0 \pm 9.00$ & $168.7 \pm 7.76$ & $167.0 \pm 11.00$ & $166.9 \pm 7.94$ & $166.0 \pm 11.75$ & $0.006^{\mathrm{a}}$ \\
\hline BMI (kg/m²) & $28.3 \pm 8.98$ & $26.3 \pm 12.40$ & $27.9 \pm 4.52$ & $26.6 \pm 6.40$ & $27.9 \pm 5.69$ & $26.6 \pm 6.77$ & 0.674 \\
\hline BMR (kcal) & $1370.7 \pm 354.66$ & $1295.0 \pm 154.30$ & $1526.6 \pm 170.50$ & $1545.0 \pm 218.00$ & $1491.5 \pm 229.2$ & $1488.0 \pm 272.00$ & $0.004^{\mathrm{a}}$ \\
\hline Waist/hip ratio & $0.9 \pm 0.07$ & $0.9 \pm 0.10$ & $0.9 \pm 0.05$ & $0.9 \pm 0.07$ & $0.9 \pm 0.05$ & $0.9 \pm 0.07$ & 0.435 \\
\hline Fat mass (kg) & $25.9 \pm 10.73$ & $27.6 \pm 15.60$ & $27.4 \pm 11.89$ & $25.6 \pm 13.60$ & $27.1 \pm 11.53$ & $26.1 \pm 13.60$ & 0.796 \\
\hline Fat $(\%)$ & $35.6 \pm 10.57$ & $37.6 \pm 20.00$ & $31.9 \pm 6.33$ & $31.1 \pm 10.10$ & $32.8 \pm 7.49$ & $31.4 \pm 10.90$ & 0.271 \\
\hline $\begin{array}{l}\text { Lean body } \\
\text { mass (kg) }\end{array}$ & $46.3 \pm 16.43$ & $42.8 \pm 7.10$ & $53.6 \pm 7.89$ & $54.4 \pm 10.10$ & $51.9 \pm 10.61$ & $51.8 \pm 12.60$ & $0.004^{\mathrm{a}}$ \\
\hline $\begin{array}{l}\text { Total body } \\
\text { water }(\mathrm{kg})\end{array}$ & $33.5 \pm 10.55$ & $31.4 \pm 5.20$ & $39.6 \pm 5.81$ & $40.2 \pm 7.30$ & $38.2 \pm 7.44$ & $38.4 \pm 9.10$ & $0.004^{\mathrm{a}}$ \\
\hline $\begin{array}{l}\text { Skeletal-muscle } \\
\text { weight }(\mathrm{kg})\end{array}$ & $26.8 \pm 13.37$ & $22.9 \pm 4.60$ & $29.5 \pm 4.66$ & $30.1 \pm 5.40$ & $28.9 \pm 7.16$ & $28.8 \pm 7.40$ & $0.009^{\mathrm{a}}$ \\
\hline $\begin{array}{l}\text { Intracellular } \\
\text { fluid amount (1) } \\
\text { Extracellular }\end{array}$ & $21.5 \pm 9.74$ & $19.1 \pm 3.80$ & $24.2 \pm 3.58$ & $24.6 \pm 4.10$ & $23.6 \pm 5.53$ & $23.4 \pm 6.02$ & $0.004^{\mathrm{a}}$ \\
\hline fluid amount (1) & $12.0 \pm 1.10$ & $12.3 \pm 1.90$ & $15.4 \pm 2.25$ & $15.6 \pm 2.80$ & $14.6 \pm 2.49$ & $14.7 \pm 3.78$ & $0.000^{\mathrm{a}}$ \\
\hline
\end{tabular}

${ }^{a}$ Differences of anthropometric measurements between genders was compared and it was found statistically important $(\mathrm{P}<0.05)$. IQR, interquartile range; BMI, body mass index; BMR, basal metabolic rate.

regard to vitamins A, E, C and B complex intakes. The results indicated that female patients met only $59.8 \%$ of their folic acid requirement, while male patients met only $42.6 \%$ of their calcium requirement. The calcium intake of female patients was found to be significantly higher than the male patients $(\mathrm{P}=0.03)$.

Statistically significant differences were not observed between the plasma ghrelin levels and food intakes in the patients with COPD ( $\mathrm{P}>0.05$; Table IV). Correlations between plasma orexin-A levels and a number of dietary nutrient intakes are shown in Fig. 3. Plasma orexin-A levels were detected to be higher in patients with a higher dietary total fibre intake ( $r=0.303, P=0.022$; Fig. 3A). Similarly, a higher dietary intake of soluble $(\mathrm{r}=0.033, \mathrm{P}=0.029)$ and insoluble fibre $(\mathrm{r}=0.335, \mathrm{P}=0.024)$ was found to be accompanied with higher plasma orexin-A levels (Fig. 3B and C). A similar correlation was observed between the daily calcium intake and plasma orexin-A levels ( $\mathrm{r}=0.065, \mathrm{P}=0.046$; Fig. 3D; Table IV).

\section{Discussion}

Malnutrition is a life-threatening health issue that is commonly observed in patients with COPD (3-8). Previous studies have demonstrated that the reason for these individuals being underweight is an imbalance between their energy expenditure and intake. Studies concerning the regulation of body weight emphasise the involvement of energy expenditure and appetite physiology, particularly neuropeptides that affect the nutritional status (24-26). The present study is of particular importance as, to the best of our knowledge, it is the first study investigating the association between plasma orexin-A and ghrelin levels, which are important polypeptides that stimulate 


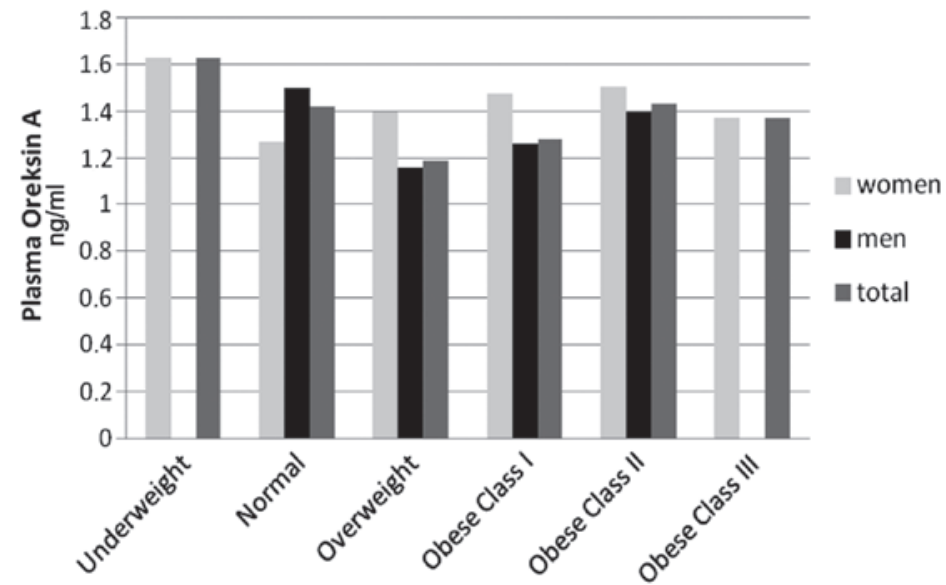

Figure 1. Distribution of plasma orexin-A levels according to patient BMI (P>0.05). BMI, body mass index.

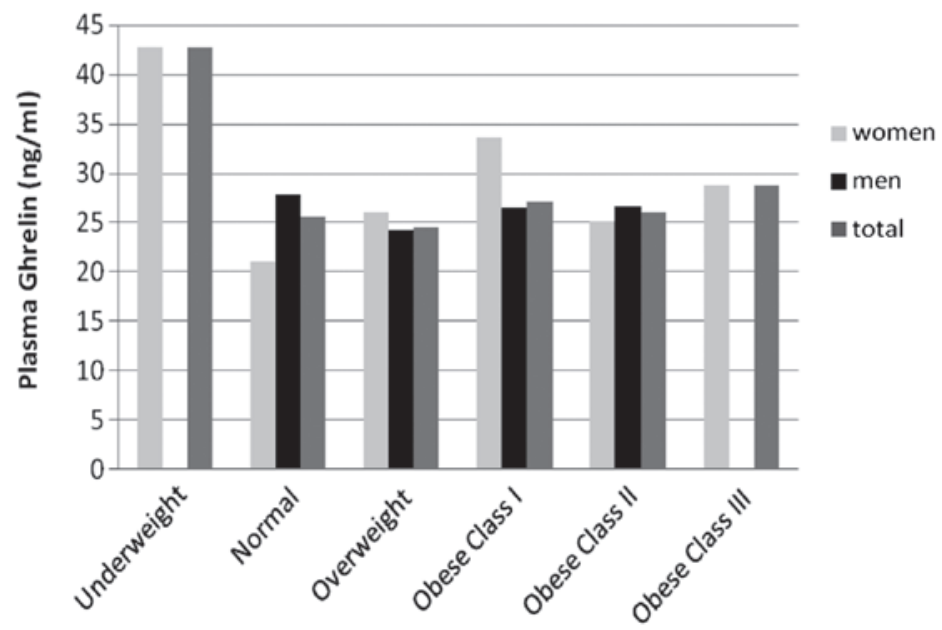

Figure 2. Distribution of plasma ghrelin levels according to patient BMI $(\mathrm{P}>0.05)$. BMI, body mass index.

food intake, with food consumption and body composition in patients with COPD in Turkey.

Previous studies on the association between plasma ghrelin levels with BMI and body composition in patients with COPD revealed contradictory results. Itoh et al (16) conducted a study to determine the plasma levels of ghrelin in patients with COPD and reported that plasma ghrelin levels of underweight patients with COPD were higher than those of normal weight individuals. In addition, a study conducted in China reported that total and active ghrelin levels in underweight patients with COPD were significantly higher when compared with normal weight COPD patients and the control group (27). In the present study, plasma ghrelin levels were highest in underweight female patients and lowest in female patients who had a normal BMI (P>0.05; Fig. 2). However, as the number of underweight female patients was not sufficient, they were not included in the statistical evaluation. In the study by Luo et al (28), plasma ghrelin levels were shown to positively correlate with the BMI and body fat percentage in patients with COPD and negatively correlate in control group patients. However, no significant correlation between the BMI and plasma ghrelin levels was observed in the present study (P>0.05; Fig. 2). Thus, further studies are required to fully elucidate the association between the plasma ghrelin levels and BMI in patients with COPD.

Matsuma et al (8) investigated plasma orexin-A levels in 20 patients with COPD and reported the plasma orexin- $A$ levels of normal weight patients as $17.5 \pm 0.9 \mathrm{pg} / \mathrm{ml}$ and underweight patients as $14.1 \pm 0.5 \mathrm{pg} / \mathrm{ml}$. Furthermore, the authors reported that plasma orexin-A levels positively correlated with $\mathrm{BMI}$ and body fat tissue $(\mathrm{BMI}, \mathrm{r}=0.49, \mathrm{P}=0.03$; body fat tissue, $\mathrm{r}=0.53, \mathrm{P}=0.02$ ). These results indicated that plasma orexin- $\mathrm{A}$ levels may have an effect on the body composition of patients with COPD (8). However, in the present study, a statistically significant difference in plasma orexin-A levels with regard to $\mathrm{BMI}$ was not identified ( $\mathrm{P}>0.05$; Fig. 1). Although limited studies have focused on the association between plasma orexin-A levels and BMI in patients with COPD, studies on obese individuals have reported a negative correlation between BMI and plasma orexin-A levels $(29,30)$.

The nutritional status of patients with COPD is an important factor that affects the onset of symptoms and prognosis of the disease. An increase in the oxygen demand in these patients also increases their energy requirement (31). However, the medication administered and short and frequent ventilation leads to insufficient food consumption (32). In a 


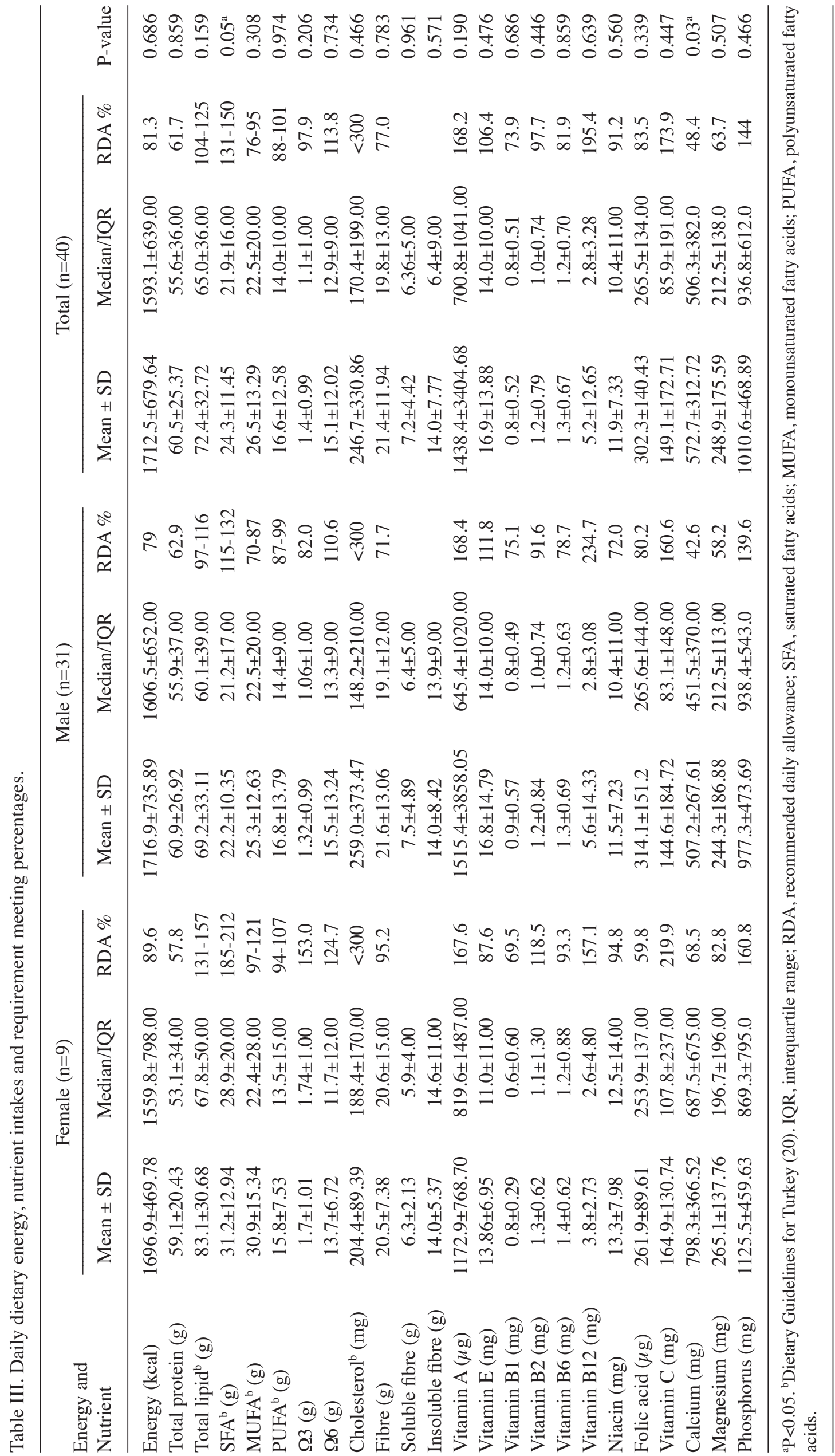


Table IV. Regression models between plasma orexin-A levels and the daily dietary intake of nutrients.

\begin{tabular}{lccc}
\hline $\begin{array}{l}\text { Plasma orexin-A } \\
\text { associated parameters }\end{array}$ & Constant & Regression Coefficient & 0.022 \\
\hline Fibre & 1.082 & 0.0100 & 0.029 \\
Soluble fibre & 1.081 & 0.0150 & 0.024 \\
Insoluble fibre & 1.104 & 0.0268 & 0.046 \\
Calcium & 1.140 & 0.0003 & 0.040 \\
\hline
\end{tabular}

When the statistical analyses were examined, simple linear regression models were created to estimate the plasma orexin-A values from the values of the associated parameters. The models shown in Table IV were found to be statistically significant $(\mathrm{P}<0.05)$.

A

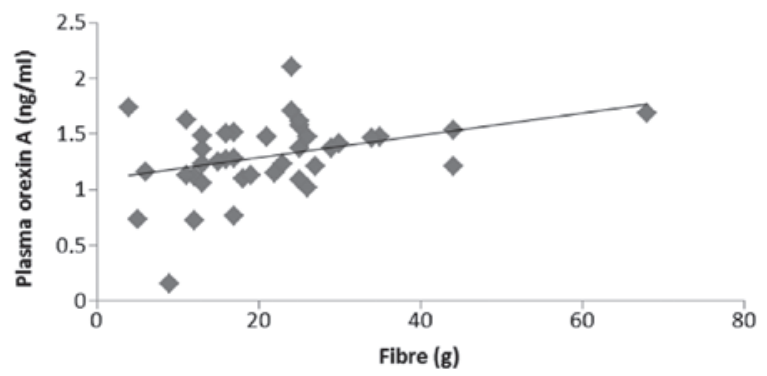

$\mathbf{B}$

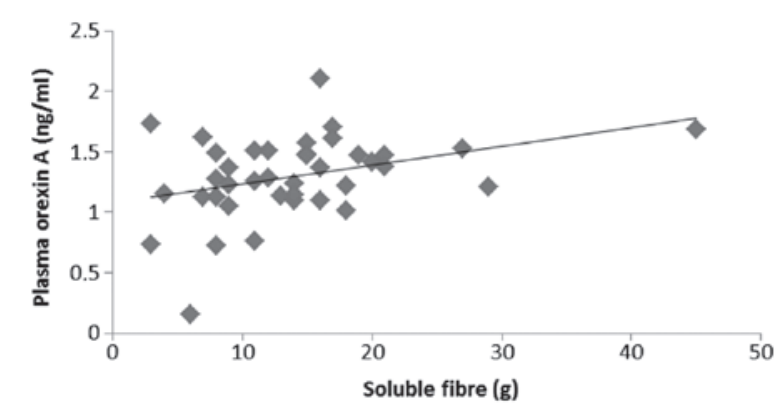

C

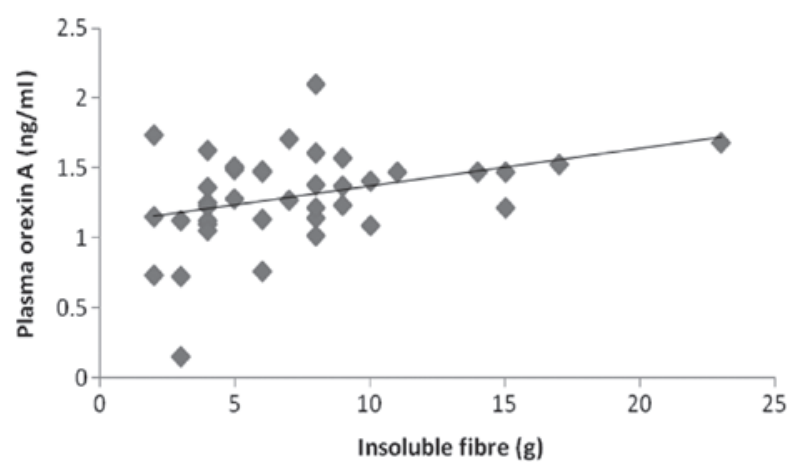

D

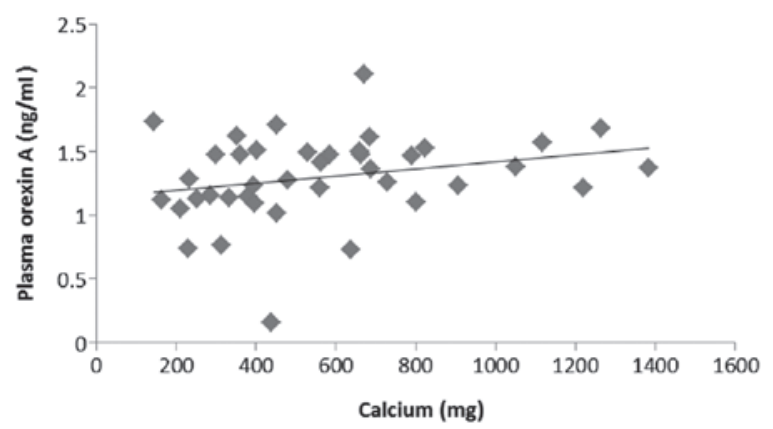

Figure 3. Correlation between plasma orexin-A levels and (A) daily dietary fibre intake $(\mathrm{P}=0.022, \mathrm{r}=0.303)$, (B) dietary soluble fibre intake $(\mathrm{P}=0.029$, $\mathrm{r}=0.033)$, (C) dietary insoluble fibre intake ( $\mathrm{P}=0.024, \mathrm{r}=0.335)$, and (D) dietary calcium intake $(\mathrm{P}=0.046, \mathrm{r}=0.065)$. 
study conducted on 41 patients with COPD, individuals were found to have an insufficient energy intake (33). In addition, a study on 251 patients with COPD in Korea determined that the COPD patients met $66.76 \%$ of their daily energy requirement (31). In the present study, it was observed that patients with COPD met $81.3 \%$ of their daily energy requirement (Table III). Although malnutrition is commonly observed in COPD patients, it is positive that they meet the majority of their energy requirements. However, the protein, calcium and magnesium intakes, which may have an effect on muscle strength and respiratory functions, were found to be insufficient (Table III). Therefore, planning and implementation of nutritional therapy is of vital importance in COPD and requires dietician support.

Orexin contributes to respiratory control via increasing ventilation (32). Plasma orexin-A levels differ in COPD patients in the stable phase and in the situation of hypercapnic respiratory failure. While Matsumura et al (8) reported that patients with COPD in stable phase had lower plasma orexin-A levels compared with a control group, Zhu et al (34) reported that COPD patients with hypercapnic respiratory failure had higher plasma orexin levels compared with normal individuals.

Dietary nutrient intakes have been shown to affect the respiratory functions of patients with COPD $(35,36)$. In particular, dietary fibre intake in adults is considered to have beneficial effects on chronic respiratory symptoms (37). However, sufficient information concerning an association between fibre consumption with pulmonary functions and COPD has not been demonstrated. In a previous study, individuals with the highest fibre consumption were reported to have higher forced expiratory volumes in one second compared with other individuals. Furthermore, a positive correlation has been demonstrated between the plasma levels of certain nutritional elements, including vitamin $\mathrm{C}$, vitamin $\mathrm{D}$, calcium, vitamin $\mathrm{E}$, and respiratory coefficients (38). In a study conducted on 278 adults, the daily dietary intake of calcium and the risk of developing of COPD exhibited a negative correlation (34).

In the present study, the daily dietary intake of fibre and calcium, which positively affect pulmonary functions, and plasma orexin-A levels were demonstrated to be positively correlated. This correlation is hypothesised to have arisen from the effects of orexin-A, as well as fibre and calcium, on respiratory functions. As the number of studies on this subject is limited, the results of the present may provide useful information for future studies.

\section{References}

1. Gudmundsson G, Gislason T, Lindberg E, et al: Mortality in COPD patients discharged from hospital: the role of treatment and co-morbidity. Respir Res 7: 109, 2006.

2. Hurd S: The impact of COPD on lung health worldwide: epidemiology and incidence. Chest 117 (2 Suppl): 1S-4S, 2000.

3. Engelen M, Schols AM, Baken WC, et al: Nutritional depletion in relation to respiratory and peripheral skeletal muscle function in out-patients with COPD. Eur Respir J 7: 1793-1797, 1994.

4. Mostert R, Goris A, Weling-Scheepers C, et al: Tissue depletion and health related quality of life in patients with chronic obstructive pulmonary disease. Respir Med 94: 859-867, 2000.

5. Wilson DO, Rogers RM, Wright EC and Anthonisen NR: Body weight in chronic obstructive pulmonary disease: The National Institutes of Health Intermittent Positive-Pressure Breathing Trial. Am Rev Respir Dis 139: 1435-1438, 1989.
6. Gray-Donald K, Gibbons L, Shapiro SH, Macklem PT and Martin JG: Nutritional status and mortality in chronic obstructive pulmonary disease. Am J Respir Crit Care Med 153: 961-966, 1996.

7. Landbo C, Prescott E, Lange P, Vestbo J and Almdal TP: Prognostic value of nutritional status in chronic obstructive pulmonary disease. Am J Respir Crit Care Med 160: 1856-1861, 1999.

8. Matsumura T, Nakayama M, Satoh H, Naito A, Kamahara K and Sekizawa K: Plasma orexin-A levels and body composition in COPD. Chest 123: 1060-1065, 2003.

9. Vermeeren MA, Creutzberg EC, Schols AM, Postma DS Pieters WR, Roldaan AC and Wouters EF; COSMIC Study Group: Prevalence of nutritional depletion in a large out-patient population of patients with COPD. Respir Med 100: 1349-1355, 2006.

10. Briski KP and Sylvester PW: Hypothalamic orexin-A-immunopositive neurons express Fos in response to central glucopenia. Neuroreport 12: 531-534, 2001.

11. Gezmen Karadağ M and Aksoy M: The effect of omega-3 fatty acid supplementation on plasma orexin A, plasma fatty acids, and anthropometric measurements in patients with narcolepsy. Turk J Med Sci 42: 77-88, 2012.

12. Lazarczyk MA, Lazarczyk M and Grzela T: Ghrelin: a recently discovered gut-brain peptide (review). Int J Mol Med 12: 279-287, 2003.

13. Cummings DE: Ghrelin and the short- and long-term regulation of appetite and body weight. Physiol Behav 89: 71-84, 2006.

14. Liu ZB, Song NN, Geng WY, Jin WZ, Li L, Cao YX, Qian Y, Zhu DN and Shen LL: Oreksin-A and respiration in a rat model of smoke-induced chronic obstructive pulmonary disease. Clin Exp Pharmacol Physiol 37: 963-968, 2010.

15. Ying BW, Song XB, Fan H, Wang LL, Li YS, Cheng Z, Cheng H and Wen FQ: Plasma ghrelin levels and weight loss in Chinese Uygur patients with chronic obstructive pulmonary disease. J Int Med Res 36: 1371-1377, 2008.

16. Itoh T, Nagaya N, Yoshikawa M, Fukuoka A, Takenaka H, Shimizu Y, Haruta Y, Oya H, Yamagishi M, Hosoda H, Kangawa $\mathrm{K}$ and Kimura $\mathrm{H}$ : Elevated plasma ghrelin level in underweight patients with chronic obstructive pulmonary disease. Am J Respir Crit Care Med 170: 879-882, 2004.

17. Phoenix Pharmaceuticals: General protocol for EK-031-50. http:// www.phoenixpeptide.com/catalog/product_info.php?products_ id=10814. Accessed August 15, 2013.

18. Phoenix Pharmaceuticals: General protocol for EKE-003-30. and http://www.phoenixpeptide.com/catalog/product_info. php?products_id=9380. Accessed August 15, 2013.

19. Rakicıŏ̆lu N, Acar Tek N, Ayaz A and Pekcan G: Yemek ve Besin Fotoğraf Kataloğu. 3rd edition. Ata Ofset Press, Ankara, Turkey, pp.35-79, 2012.

20. Dietary reference intakes for energy, carbohydrate, fiber, fat, fatty acids, cholesterol, protein and amino acid. Washington DC, USA: Institute of Medicine of the National Academies, 2001. http://www.iom.edu/reports/2002/ dietary-reference-intakes-for-energy-carbohydrate-fiberfat-fatty-acids-cholesterol-protein-and-amino-acids.aspx. Accessed July 20, 2013.

21. The Ministry of Health of Turkey The General Directorate of Primary Health Care and Hacettepe University Department of Nutrition and Dietetics: Dietary guidelines for Turkey. http://www.beslenme.gov.tr/content/files/yayinlar/ingilizce yayinlar/books/dietary_guidelines.pdf. Accessed August 15 , 2013.

22. World Health Organisation: BMI classification. http://apps.who. int/bmi/index.jsp?introPage $=$ intro_3.html. Accessed June 15, 2013.

23. Özdamar K: (2004). Paket programlar ile istatistiksel veri analizi (Cilt 1). Eskisehir: Kaan Kitapevi.

24. Schols AM, Soeters PB, Mostert R, et al: Energy balance in chronic obstructive pulmonary disease. Am Rev Respir Dis 143: 1248-1252, 1991.

25. Inui A: Cancer anorexia-cachexia syndrome: are neuropeptides the key? Cancer Res 59: 4493-4501, 1999.

26. Kalra SP, Dube MG, Pu S, et al: Interacting appetite-regulating pathways in the hypothalamic regulation of body weight. Endocr Rev 20: 68-100, 1999.

27. Peng M, Cai BQ, Ma Y, Zhu HJ, Sun Q and Song AL: Circulating leptin and ghrelin in patients with chronic obstructive pulmonary disease. Zhonghua Jie He He Hu Xi Za Zhi 30: 182-185, 2007 (In Chinese). 
28. Luo FM, Liu XJ, Li SQ, Wang ZL, Liu CT and Yuan YM: Circulating ghrelin in patients with chronic obstructive pulmonary disease. Nutrition 21: 793-798, 2005.

29. Baranowska B, Wolińska-WitortE,Martyńska L,Chmielowska M and Baranowska-Bik A: Plasma orexin A, orexin B, leptin, neuropeptide Y (NPY) and insulin in obese women. Neuro Endocrinol Lett 26: 293-296, 2005.

30. Adam JA, Manheere PP, van Dielen FM, Soeters PB, Buurman WA and Greve JW: Decreased plasma orexin-A levels in obese individuals. Int J Obes Relat Metab Disord 26: 274-276, 2002.

31. Lee H, Kim S, Lim Y, Gwon H, Kim Y, Ahn J and Park H: Nutritional status and disease severity in patients with chronic obstructive pulmonary disease (COPD). Arch Gerontol Geriatr 56: 518-523, 2013.

32. Woo J, Mak YT and Swaminathan R: Nutritional status of general medical patients - influence of age and disease. J Nutr Biochem 2: 274-280, 1991

33. Hallin R, Koivisto-Hursti U,Lindberg E and Janson C: Nutritional status, dietary energy intake and the risk of exacerbations in patients with chronic obstructive pulmonary disease (COPD). Respir Med 100: 561-567, 2006.
34. Zhu LY, Summah H, Jiang HN and Qu JM: Plasma orexin-a levels in COPD patients with hypercapnic respiratory failure. Mediators Inflamm 2011: 754847, 2011.

35. McKeever TM, Lewis SA, Smit HA, Burney P, Cassano PA and Britton J: A multivariate analysis of serum nutrient levels and lung function. Respir Res 9: 67, 2008.

36. Hirayama F, Lee AH, Oura A, Mori M, Hiramatsu N and Taniguchi H: Dietary intake of six minerals in relation to the risk of chronic obstructive pulmonary disease. Asia Pac J Clin Nutr 19: 572-577, 2010.

37. Kan H, Stevens J, Heiss G, Rose KM and London SJ: Dietary fiber, lung function and chronic obstructive pulmonary disease in the atherosclerosis risk in communities study. Am J Epidemiol 167: 570-578, 2008.

38. Young JK, Wu M, Manaye KF, Kc P, Allard JS, Mack SO and Haxhiu MA: Orexin stimulates breathing via medullary and spinal pathways. J Appl Physiol (1985) 98: 1387-1395, 2005 